\title{
Effects of Road Improvement on Safety: A Case Study of Nairobi-Thika Superhighway
}

\author{
Chelugo Nicholas Chepchieng ${ }^{1, ~}{ }^{*}$, Abiero Gariy ${ }^{1}$, Mwatela Josphat K. Z. ${ }^{2}$ \\ ${ }^{1}$ Department of Civil, Construction and Environmental Engineering, Jomo Kenyatta University of Agriculture and Technology, Nairobi, \\ Kenya \\ ${ }^{2}$ Department of Geomatic Engineering and Geospatial Information Systems, Jomo Kenyatta University of Agriculture and Technology, \\ Nairobi, Kenya
}

Email address:

engchelugo@gmail.com (C. N. Chepchieng)

\section{To cite this article:}

Chelugo Nicholas Chepchieng, Abiero Gariy, Mwatela Josphat K. Z. Effects of Road Improvement on Safety: A Case Study of Nairobi-Thika Superhighway. American Journal of Civil Engineering. Vol. 3, No. 6, 2015, pp. 199-206. doi: 10.11648/j.ajce.20150306.11

\begin{abstract}
Road safety is one of the main transportation problems in developing countries. The major goal of the transportation system is to enhance mobility and road traffic accidents are unwanted by-products which have to be minimized while achieving the primary goal. Road safety engineers are faced with the challenge of addressing safety issues within the three major traffic safety pillars: human, vehicle, and infrastructure.All three aspects must be part of a traffic safety plan and dealt with subject to budget limitations. The project involved redesigns of all intersections and increment in the road lanes to enhance capacity and improve safety. The research study aimed to review the occurrences of crashes on the improved ThikaNairobi superhighway in three phases; before, during and after construction. This research sought to assess the role of incorporation of different safety measures in road projects in Kenya and is anticipated to improve public awareness on the use of road safety provisions with the aim of reducing road traffic accidents and subsequent casualties. The approach used to realize this study involved gathering data from traffic police stations, conducting interviews to get the opinions of road users on safety and making observations on the turning movements of vehicles and pedestrians. The interactions were explored, analysed and modelled using Chi-squared distribution. These were then used to identify accident black spots and assess the effectiveness of road safety measures installed in the new super highway. This study revealed that the large number of accidents occurred in the years before and at the start of construction, reduced during construction and increased again after completion. The primary type of accidents along the highway is vehicle to pedestrian and vehicle to vehicle. Githurai 45 , Safari park and G.S.U were established to be black spots. The most efficient road facility was found to be foot paths, and foot bridges.
\end{abstract}

Keywords: Black Spots, Nairobi-Thika Superhighway, Road Crash, Road Safety, Traffic Accidents

\section{Introduction}

Many countries have set ambitious quantified road safety targets [1]. Targets alone cannot guarantee enhanced safety but they can enhance implementation of cost-effective safety measures. To be able to build up a realistic and effective safety programme, the measures must be selected using latest scientific knowledge on their effects. Scientific research has produced lots of good estimates on the effects of safety improving measures. The effects are usually presented as a percentage change in the number of injury accidents. So it is vital to be able to evaluate reliably what would have happened if the road safety measure had not been implemented. In addition experience suggests that the greatest mistakes in evaluating the safety effects of road improvements are done while evaluating the current safety situation. It is a challenge to develop effective measures for improving road safety especially when resources are scarce and economic means are limited. Nevertheless, a major target for European policy as well for as for national, regional and local decision makers is to improve road safety significantly in our roads [2].

The Nairobi-Thika Highway is one of three major corridors linking downtown Nairobi to the suburbs and satellite towns. Traffic demand on this road is almost twice the existing capacity. Accident data shows that over the past five years more than 700 accidents occurred on the Nairobi 
Thika road of these 227 were fatal. The upgrading of the highway, therefore, will provide adequate capacity and considerably decrease the accident rate by minimizing vehicle conflicts with traffic interchanges and by providing separate service roads for local and non-motorized traffic. The completed $45 \mathrm{~km}$ Nairobi-Thika superhighway design highlights comprises of six to eight-lane divided highway with full access control between Nairobi and Thika Town built services roads along the Highway built with nine traffic interchanges built. The overall objectives of the improvement project were to Contribute to and improve the accessibility, affordability, and reliability of the transport infrastructure system to promote economic growth and socio-economic development in Kenya Contribute to regional integration in the eastern and horn of Africa regions,Improve road transport services along the Nairobi-Thika corridor and enhance urban mobility within the metropolitan area by reducing traffic congestion, Contribute to the development of a sustainable urban public transit system for the Nairobi Metropolitan Area and finally to promote private sector participation in the management, operation, and financing of road infrastructure in Kenya.

Rapid urbanisation and motorisation in Kenya have fuelled urban mobility demand, threatening long term sustainability of urban areas. Nairobi's population has grown significantly from 350,000 in 1963 to $828,000,1,325,000$ and 2,137000 in 1979, 1989 and 1999 respectively.Its night time population by 2007 is estimated at 3.05 million and is growing at a rate higher than even the national population growth (4.8 per cent as compared to 3.4 per cent.The current population of Nairobi Metropolis is projected at 4.73 million [3].Notably, Nairobi's population represents about 21 per cent of Kenya's urban population.A feature not to be ignored also is Nairobi's primacy; Mombasa the second largest city has a population of 660,000 representing approximately $25 \%$ of Nairobi's population.Projections indicate that this population is expected to hit the 8 million mark by the year 2030. With the expected population increment it is expected that demand for fast, safe, efficient and secure transport system shall also go up and consequently increase in chances of road traffic accidents and crashes. According to [4] road transport sector has been increasing from $36.9 \%$ in 1997 to $65.3 \%$ in 2009 as a share of total transportation sector hence the need to have a reliable road crashes data system which is very important for desirable road safety practice. It is, therefore, paramount to examine how road improvement as exemplified by ThikaNairobi Superhighway affects safety on the roads.

\section{Statement of the Problem}

Globally, it is estimated that on average, road traffic accidents cost up to $1 \%$ of a country's Gross Domestic Production (GPD), and the Sub-Saharan Africa has the highest road accident death rates in terms of fatalities per registered vehicle, as compared to any other region in the world [5]. It is also reported that road safety in the African region is a major social and economic concern in that although the region has about $4 \%$ of the world's motor vehicles, $11 \%$ of the world's reported fatalities are due to RTAs. Further, the cost of road traffic accidents was crudely estimated to be US $\$ 3.7$ billion in 1997 in this same report [6]. The road accidents impact massively on both the health and insurance sectors whereby the cost implication is very high and slices a huge share of Kenya's GDP. In spite of this, there is poor accident and crash costing which downplays the critical role road safety plays and thereby undermines the urgency and vigour with which safety measures should be undertaken.

In Kenya road accidents account for the loss of more than 3,000 lives annually, a significant proportion of these are young and productive men and women in the 15-45 years age bracket. The economic cost of such road accidents and fatalities has been estimated to be in excess of 4 billion shillings. Kenya has one of the highest rates of accident in the world at present with 510 fatal accidents for every 100,000 registered vehicles. With the high growth of road accidents in Kenya, it is essential that adequate sums of money be spent in dealing with the problem. In the absence of an estimate of accident-related economic issues, it is difficult to identify the sums of money that should be invested each year on road safety countermeasures. Nevertheless, Theestimation of the national explicit costs of road accidents as well as the implicit value of the accidents is rarely highlighted to policy makers. In light of this, the present study is aimed to shed more light on the cost of traffic accidents whereby the findings will help to evaluate the effectiveness of road safety programs as well as in the proper allocation of the country's limited financial resources for the most effective prevention plans.

\section{Study Objective}

To assess the effects of road improvement on safety along the $45 \mathrm{~km}$ Thika Superhighway.

\section{Research Hypothesis}

$H_{0}$ : Road rehabilitation improves road safety and reduces road crash rates and frequencies.

\section{Literature Review}

\subsection{Characteristics of Crashes}

The Highway Safety Manual (HSM) defines safety as "the crash frequency and/or crash severity and collision type for a specific time period, a given location, and a given set of geometric and operational conditions". Safety is defined in similar terms by the American Association of State Highway and Transportation Officials [7]. Roadway safety is usually defined and evaluated in terms of the number of recorded crashes. Crash severity also plays an important role in understanding roadway safety. For example, one site may experience considerably more crashes than another; however, the second site may have a much larger proportion of severe, 
particularly fatal, crashes. Therefore, both crash frequency and crash severity are essential in determining the safety of a facility. In order to understand how to reduce crash frequency and crash severity, it becomes important to first understand the factors behind crashes.

\subsection{Causes of Crashes}

Crashes represent a very small proportion of all of the events that occur on a transportation system. There have been numerous proposed theories that try to explain the causes of crashes. The Handbook of Road Safety Measures [1] provides a more in-depth look at various proposed theories. In this research, it is sufficient to emphasize four conclusions that can be made from these theories. First, it is probable that all proposed crash theories have an element of truth in them. However, while crash cause theories do include portions of the truth, none of the theories provide a complete understanding or explanation of why crashes occur. One of the key reasons it is difficult to understand why crashes occur is because crashes are usually not the result of one factor, but the combination of multiple events, circumstances, and [8]. There are three categories of factors that contribute to crashes [7]. These include:

i. Human - including age, judgment, driver skill, attention, fatigue, experience and sobriety

ii. Vehicle - including design flaws, safety features

iii. Roadway/Environment - including geometric alignment, cross-section, traffic control devices, surface friction, grade, signage, weather and visibility.

The combination of multiple events can severely alter the amount of risk a driver may face. For example, imagine a deer runs in front of a driver on a rural highway. Driver A, driving during the daytime, is at considerably less risk than Driver B, driving at night during a snowstorm. Driver A may have to deal with factors such as reaction time, stopping distance, and brake wear. Driver B would be affected by the same factors in addition to reduced surface friction and visibility. Understanding this point helps to understand that crashes are the outcome of a vastly complex random process [8].

Secondly, there are certain roadway, vehicle, and driver trends that make the occurrence of a crash more likely. The exact impact these trends have on roadway safety has long been the focus of research. Difficulty arises due to the fact that some are known, while others are not. Third, it is also important to understand that even though improvements are continually made to reduce crash frequency, no system is entirely perfect. Drivers are fallible and thus still subject to error in judgment, whether recklessly or not. This provides great difficulty in determining the effectiveness of an improvement [8]. Finally, even if it were possible to account for all crash factors, the ability to predict a crash is not absolute. The reason is that crashes are still to some extent a random event [8].

The key principle is that understanding the nature of crashes is a vastly complex and random process when considering just the known factors. It is important to remember that there are factors that contribute to crashes that are unknown. The premature assumption might then be made that limited understanding of the contributing factors of crashes make it extremely difficult, if not impossible, to determine the proper remedy for crashes. The Handbook of Road Safety Measures, [1] provides valuable insight in understanding the concept of crash causes. The handbook states "the logic of the argument that you need to know the causes of a problem in order to solve it seems irresistible. Yet, as far as crashes are concerned, there is not necessarily a very close connection between the causes of the problem and its solution" [1]. The complexity of known and unknown contributing factors can be overcome through the development and use of proper statistical tools that correctly model crash characteristics and behavior.

\subsection{Crash Rate}

In order to model crashes, it is necessary to first define what exactly is being measured. Traditional practice has been to use crash rates as a measure of safety [9]. The crash rate is the frequency of crashes adjusted to account for volume or exposure. The general relationship between crash frequency and crash rate is explained in Equation 1.

$$
\text { Crashrate }=\frac{\text { averagecrashfrequencyinperiod }}{\text { duringtheperiodofexposure }}
$$

Crash rates for road segments are typically reported in crashes per million vehicle miles traveled (MVMT) or per hundred MVMT. Crash rates for intersections are typically reported in crashes per million entering vehicles (MEV). Equation 2 shows the crash rate equation for a section of roadway [9].

$$
\text { CRsec }=\frac{\mathrm{N}}{\operatorname{Vsec} \times 365 \times \mathrm{L}} \times 10^{6}
$$

Where:

$\mathrm{CR}_{\mathrm{sec}}=$ crash rate for section (in crashes per MVMT),

$\mathrm{N}=$ number of crashes per year,

$\mathrm{V}_{\mathrm{sec}}=$ average annual daily traffic (AADT) of road section, and

$\mathrm{L}=$ length of section (in miles)

Equation 3 shows the crash rate equation for intersections.

$$
\text { CRint }=\frac{\mathrm{N}}{\operatorname{Vsec} \times 365 \times \mathrm{L}} \times 10^{6}
$$

Where:

$\mathrm{CR}_{\mathrm{int}}=$ crash rate for intersection (in crashes per MEV), and

$\mathrm{V}_{\text {int }}=$ sum of average daily approach volumes of intersection.

When using crash rates, an assumption is often made that the relationship between frequency and exposure is linear. Recent studies have shown that this assumption is not always valid [10]. It has been determined that the use of crash frequency is a more accurate indicator of roadway safety than the use of crash rates. Research shows that the relationship between traffic volume and crash count is more 
complex and relates to quantities such as the distribution of traffic throughout the day and the types of crashes experienced. Some studies have indicated that there is indeed a relationship between the number of crashes and traffic volume [11]. The exact form, however, is still unknown and likely depends on crash type. Models using aggregate data (not separated by crash type) and exposure as inputs ignore significant variation in highway crashes resulting from hourly volume changes and human behavioral changes throughout the day. A study performed using disaggregate data (crashes broken down by type) revealed how the relationship between crashes and traffic volumes varies from location to location and by crash type [12]. New approaches are also being developed for incorporating traffic volumes in crash rate analysis and forecasting studies [8].

\subsection{Crash Frequency}

One solution that overcomes the non-linear relationship between crash frequency and exposure associated with crash rates is to use crash frequency as the fundamental basis for safety analysis and measurement of treatment effectiveness [7]. The use of crash frequency as a measure of safety eliminates the inclusion of exposure altogether. A crash frequency is obtained by counting the number of crashes at a certain site of interest, usually a roadway segment or intersection, over a certain period of time. Crash frequency and crash severity are important elements of crash history and form the basis of quantifying and measuring safety. Along with understanding these elements of crash data, it is also important to understand trends exhibited within the data so that an appropriate statistical approach can be used in analysis of crashes.

\section{Research Methodology}

Research methodology encompasses the step-by-step procedure that is followed to arrive at findings that are in tandem with the study objectives. In the context of the present study, scientific approach was adopted whereby it was thought better to regard the phenomenon of RTAs as a chance process. At any time, the road, the traffic, the user and the vehicle is a set of circumstance have a certain chance or probability of leading to an accident. The following sequence was followed during the study:

i. Field observations were conducted to establish road conditions that pose a threat to safety.Road characteristics that were of interest during the survey included cross-section, drainage, roadside, safety barriers, alignment, junctions, bus and, parking facilities, access to properties, speed management, and speed management, and pedestrian usage characteristics and provision of pedestrian facilities.

ii. Conducting interviews, and

iii. Collection of road accident data and traffic count data for the study section and its interpretation.

\subsection{Sampling}

An assumption was made that the population is unknown, thus Cochran's equation (Equation 4) was used in the determination of the sample size

$$
n_{0}=\frac{\mathrm{Z}^{2} * \mathrm{P} * Q}{e^{2}}
$$

Where: $n_{0}=$ Sample Size

$Z=Z$ score (area under the normal curve)

$\mathrm{P}=$ Estimated proportion of an attribute

(Standard Deviation)

$e=$ Desired level of precision

$$
\mathcal{Q}=1-\mathrm{P}
$$

With a $95 \%$ desired confidence level, standard deviation of 5 and a desired margin of error of $\pm 5 \%$, the sample size for this study was calculated as follows:

$$
\frac{1.96^{2} * 0.5 *(1-0.5)}{0.05^{2}}=385 \text { respondents }
$$

\subsection{Secondary Data Collection}

Road accident data used in this study was obtained from police records. The Kenya Police routinely collect and store data on motor vehicle accidents mainly for prosecution and insurance compensation purposes. The accident data used in this study was collected from Kasarani, Ruiru, and Muthaiga police stations and the traffic police headquarters. Road accident data for the year 2005 to 2013 for Thika Road; between Muthaiga roundabout and Ruiru were used. The data collected covered the pre-construction period, construction period and post-construction period of Thika Superhighway. The expected frequency and severity of crashes caused by each safety issue have been identified and rated according to the categories shown in Table 1.

Table 1. Severity Rating.

\begin{tabular}{lll}
\hline Typical Crashes Expected & $\begin{array}{l}\text { Expected } \\
\text { CrashSeverity }\end{array}$ & $\begin{array}{l}\text { Severity } \\
\text { Rating }\end{array}$ \\
\hline $\begin{array}{l}\text { Crashes involving high speeds or } \\
\text { heavy vehicles, pedestrians, or bicycles }\end{array}$ & $\begin{array}{l}\text { Probable fatality } \\
\text { orincapacitating } \\
\text { injury }\end{array}$ & Extreme \\
$\begin{array}{l}\text { Crashes involving medium to high } \\
\text { speed;Head-on, crossing, or run-off- } \\
\text { road crashes } \\
\text { crashes involving medium to low } \\
\text { speeds;Left-turn and right-turn crashes }\end{array}$ & $\begin{array}{l}\text { Moderate to } \\
\text { severe injury }\end{array}$ & $\begin{array}{l}\text { Minor to moderate } \\
\text { injury }\end{array}$ \\
$\begin{array}{l}\text { Prashes involving low to medium } \\
\text { speeds;Rear-end or sideswipe crashes }\end{array}$ & $\begin{array}{l}\text { Monly orminor } \\
\text { injury }\end{array}$ & Loderate \\
\hline
\end{tabular}

\section{Analysis and Discussions}

\subsection{Number of Accidents}

The total number of accidents recorded in the span of 8 years was 993 (Table 2). The most number of accidents occurred in the years before and at the start of construction, that is 2006 to 2009. In the following two years of construction, 2010 and 2011, the number of accidents 
reduced remarkably. This can be explained by the reduced vehicle speeds during construction. At the end of construction, that is year 2012, when most of the construction was completed, there was a $79 \%$ increase in the number of accidents over the previous year. However, the linear graph (Figure1) indicates that, in general, the number of accidents reduced over the five year period.

Table 2. Accident Data Before, During and After Construction.

\begin{tabular}{|c|c|c|c|c|c|c|c|c|}
\hline \multicolumn{9}{|c|}{ ACCIDENT DATA } \\
\hline YEAR & Ped to Veh & Veh to Road & Cyclistto Veh & Veh to Veh & Slight & Fatal & Serious & Total No of Accidents \\
\hline 2006 & 96 & 35 & 15 & 62 & 32 & 53 & 72 & 208 \\
\hline 2007 & 84 & 42 & 21 & 45 & 56 & 62 & 58 & 192 \\
\hline 2008 & 53 & 16 & 6 & 34 & 29 & 55 & 26 & 109 \\
\hline 2009 & 76 & 18 & 7 & 58 & 28 & 76 & 55 & 159 \\
\hline 2010 & 30 & 27 & 7 & 28 & 14 & 36 & 40 & 92 \\
\hline 2011 & 32 & 8 & 3 & 14 & 16 & 12 & 27 & 57 \\
\hline 2012 & 76 & 9 & 2 & 15 & 7 & 44 & 55 & 102 \\
\hline 2013 & 48 & 10 & 3 & 13 & 5 & 31 & 48 & 74 \\
\hline Grand Total & 495 & 165 & 64 & 269 & 187 & 369 & 381 & 993 \\
\hline
\end{tabular}

Source: Kenya Police (2013)

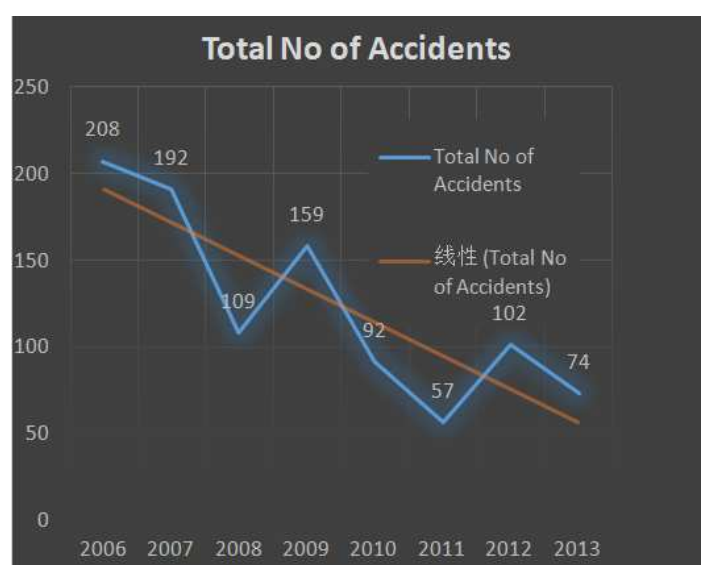

Figure 1. Total Number of Accidents and their Trend.

\subsection{Traffic Accident Severity}

Out of the 993 accidents, 39\% were fatal and 41\% were serious. The trend of slight accidents generally decreased during the 8 year period.However, that of fatal and serious accidents reduced then later increased after the completion of the project as shown in Figure 2. The fact that fatal accidents are still the most type accidents shows that additional safety measures(policy and physical)still need to be put in place and effected.

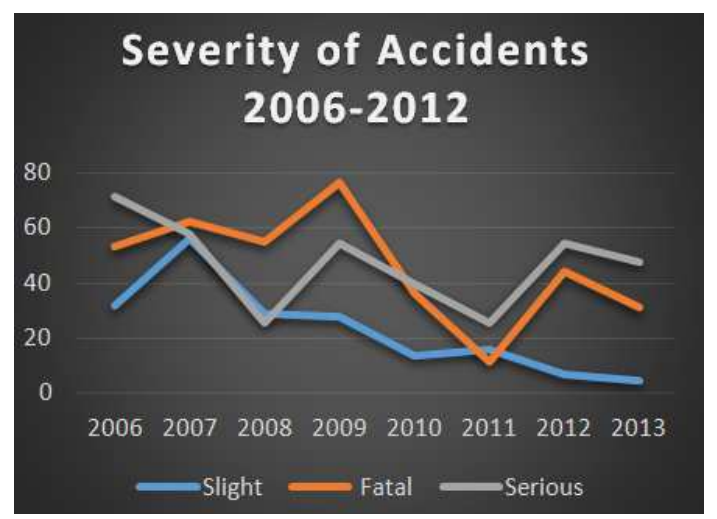

Figure 2. Severity of Accidents (2006-12).

\subsection{Types of Accidents}

The primary type of accident along the highway was found to be Vehicle to Pedestrian, $50 \%$, followed by Vehicle to Vehicle, 27\% (Chart 4.4). Pedestrians continue to be the most vulnerable road users despite installation of foot bridges, zebra crossings bumps and pedestrian foot paths along the highway. The number shot after completion of the project because of the tendency of drivers to over speed because when using a new pavement. In addition, at that time some pedestrians had the tendency of not using the facilities (foot bridges) provided for them. Some considered them cumbersome and time consuming. Vehicle to Road accidents have reduced significantly owing to the new features in the highway like additional lanes and grade intersections (Figure 3).

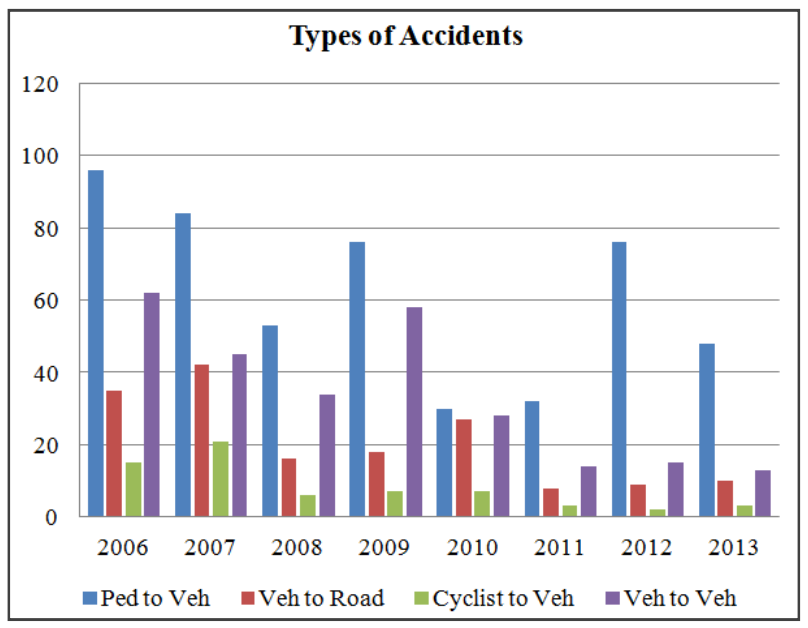

Figure 3. Types of Accidents.

\subsection{Traffic Accidents by Vehicle Type}

Small cars were the leading vehicle type in fatal, severe and slight accidents, with $40 \%$ (Table 3 ). This was partly because small cars and four wheel drives tend to be the dominant vehicle type in the daily traffic volume using the highway. Public service vehicles, that is, matatus and buses accounted for $16 \%$ and $10 \%$ respectively. 
Table 3. Traffic Accidents by Vehicle Type.

\begin{tabular}{lllll}
\hline Vehicle Type & Fatal & Serious & Slight & Total \\
\hline Bus & 14 & 17 & 10 & 82 \\
Car & 70 & 82 & 52 & 355 \\
Lorry & 21 & 21 & 7 & 69 \\
M/Cycle & 4 & 9 & 1 & 34 \\
Matatu & 26 & 39 & 31 & 136 \\
Pick Up & 7 & 17 & 4 & 34 \\
Van & 5 & 6 & 5 & 26 \\
Minubus & 8 & 7 & 1 & 65 \\
Unknown & 22 & 7 & 8 & 50 \\
Others & 2 & 1 & 1 & 23 \\
\hline
\end{tabular}

Source: Kenya Police (2015)

\subsection{Number of Accidents Versus Time of Day}

This analysis determined whether or not the number of accidents was related with the time of day. Table 4shows a calculated $\chi^{2}$ - value of 125.73 for 3 d.f. and a critical $\chi^{2}$ value of 19.675 at 0.05 confidence level. Since the calculated $\chi^{2}$ - value was found to be greater than the critical $\chi^{2}$ - value, the null hypothesis, that is, accidents are uniformly distributed over the hours of the day is rejected. Thus, it indicated that accidents were not uniformly distributed over the hours of the day before after and during construction.

Table 4. Chi Square Analysis for Goodness of fit (a).

\begin{tabular}{|c|c|c|c|c|c|c|}
\hline Hrs & Observed Frequency & Expected Frequency & D.F & Critical Chi. Sqr & Calculated Chi. Sqr & \\
\hline $0000-230$ & 15 & 43.17 & \multirow{13}{*}{11} & \multirow{13}{*}{19.675} & 18.38 & \multirow{13}{*}{125.73} \\
\hline $230-430$ & 14 & 43.17 & & & 19.71 & \\
\hline $430-630$ & 30 & 43.17 & & & 4.02 & \\
\hline $630-830$ & 37 & 43.17 & & & 0.88 & \\
\hline $830-1030$ & 48 & 43.17 & & & 0.54 & \\
\hline $1030-1230$ & 57 & 43.17 & & & 4.43 & \\
\hline $1230-1430$ & 45 & 43.17 & & & 0.08 & \\
\hline $1430-1630$ & 66 & 43.17 & & & 12.07 & \\
\hline $1630-1830$ & 62 & 43.17 & & & 8.21 & \\
\hline $1830-2030$ & 86 & 43.17 & & & 42.49 & \\
\hline $2030-2230$ & 40 & 43.17 & & & 0.23 & \\
\hline \multirow[t]{2}{*}{$2230-0000$} & 18 & 43.17 & & & 14.68 & \\
\hline & 518 & 518 & & & & \\
\hline
\end{tabular}

\subsection{Number of Accidents Versus Month of the Year}

In this analysis, whether or not the number of accidents was related to the month of year was analyzed. Table 5 shows a calculated $\chi^{2}$ - value of 23.34 for 11 degrees of freedom and a critical $\chi^{2}$ - value of 19.675 at 0.05 confidence level. Since the calculated $\chi^{2}$ - value was greater than the critical $\chi^{2}$ - value, the null hypothesis, that is, accidents are uniformly distributed over the year was rejected. Thus, it is indicated that accidents were not uniformly distributed over the year before, after and during construction.

Table 5. Chi-Square Analysis for Goodness of Fit (b).

\begin{tabular}{|c|c|c|c|c|c|c|}
\hline Month & Observed Frequency & Expected Frequency & D.F & Critical Chi. Sqr & Calculated Chi. Sqr & \\
\hline January & 35 & 42.25 & \multirow{13}{*}{11} & \multirow{13}{*}{19.675} & 1.24 & \multirow{13}{*}{23.34} \\
\hline February & 33 & 42.25 & & & 2.03 & \\
\hline March & 37 & 42.25 & & & 0.65 & \\
\hline April & 49 & 42.25 & & & 1.08 & \\
\hline May & 40 & 42.25 & & & 0.12 & \\
\hline June & 26 & 42.25 & & & 6.25 & \\
\hline July & 58 & 42.25 & & & 5.87 & \\
\hline August & 57 & 42.25 & & & 5.15 & \\
\hline September & 41 & 42.25 & & & 0.04 & \\
\hline October & 39 & 42.25 & & & 0.25 & \\
\hline November & 46 & 42.25 & & & 0.33 & \\
\hline \multirow[t]{2}{*}{ December } & 46 & 42.25 & & & 0.33 & \\
\hline & 507 & 507 & & & & \\
\hline
\end{tabular}

\subsection{Number of Accidents Versus Location}

Table 6 shows a calculated $\chi^{2}$ - value of 2008 to 2012 respectively, for 10 degrees of freedom and a critical $\chi^{2}$ - value of 10.307 at 0.05 confidence level. Since the calculated $\chi^{2}$ - value was greater than the critical $\chi^{2}$ - value, the null hypothesis that stated accidents are uniformly distributed over the whole road section was rejected. Hence, it was concluded with a $95.95 \%$ certainty that accidents black spots do exist at specific areas along Thika Road. 
Table 6. Chi-Square Analysis for Goodness of Fit (c).

\begin{tabular}{|c|c|c|c|c|c|c|c|c|c|}
\hline & Critical & 2006 & 2007 & 2008 & 2009 & 2010 & 2011 & 2012 & 2013 \\
\hline $\begin{array}{l}\text { K.U } \\
\text { Engen } \\
\text { Kahawa } \\
\text { Barracks } \\
\text { Githural } 45 \\
\text { Clayworks } \\
\text { Roysambu } \\
\text { Safaripark } \\
\text { Roasters } \\
\text { G.S.U } \\
\text { Crescent P.S } \\
\text { Total P.S }\end{array}$ & 10.307 & 39.88 & 39.84 & 22.06 & 38.56 & 36.6 & 23.9 & 73.54 & 17.51 \\
\hline
\end{tabular}

\subsection{Speed and Traffic Count Data}

An important traffic characteristic that affects safety is speed variance. A major influence on speed variance is the difference between the design speed and the posted speed limit. It has been shown that speed variance will be minimised if the posted speed limit is correlated with the design speed. This emphasises the link between posted speed limit and design speed, and supports the recommendation that speed limits should be set by a traffic engineer, based on spot speed studies. The posted speed limit along Thika road varied from $50 \mathrm{~km} / \mathrm{hr}$ to $60 \mathrm{Km} / \mathrm{hr}$. Table 7 shows the speed distribution over the different vehicle classes and the number of vehicles recorded over a $24 \mathrm{hr}$ period.

Table 7. Speed and Traffic Data Matrix.

\begin{tabular}{|c|c|c|c|c|c|c|c|c|c|}
\hline $\begin{array}{l}\text { Speed } \\
(\mathrm{Km} / \mathbf{h r})\end{array}$ & Motorcycles & Cars & Pickups/Jeeps/4WDS & Matatus/Buses & Buses & Light Trucks & $\begin{array}{l}\text { Medium } \\
\text { Trucks }\end{array}$ & $\begin{array}{l}\text { Heavy } \\
\text { Trucks }\end{array}$ & TOTAL \\
\hline $10-20$ & 299 & 1712 & 31 & 226 & 68 & 27 & 17 & 31 & 2411 \\
\hline $20-30$ & 415 & 8498 & 233 & 950 & 194 & 96 & 56 & 132 & 10574 \\
\hline $30-40$ & 618 & 27636 & 440 & 2199 & 272 & 228 & 63 & 112 & 31568 \\
\hline $40-50$ & 730 & 32423 & 326 & 1576 & 104 & 167 & 63 & 32 & 35351 \\
\hline $50-60$ & 590 & 34090 & 97 & 1017 & 73 & 63 & 29 & 9 & 35968 \\
\hline $60-70$ & 951 & 11011 & 30 & 455 & 18 & 15 & 9 & 1 & 12490 \\
\hline $70-80$ & 363 & 3887 & 3 & 139 & 4 & 10 & 4 & 1 & 4411 \\
\hline $80-90$ & 325 & 1044 & 2 & 48 & 3 & 8 & 0 & 0 & 1430 \\
\hline $90-100$ & 62 & 295 & 15 & 14 & 0 & 2 & 0 & 0 & 388 \\
\hline $100-110$ & 1 & 37 & 12 & 3 & 0 & 0 & 0 & 0 & 53 \\
\hline $110-120$ & 1 & 9 & 5 & 3 & 0 & 0 & 0 & 0 & 18 \\
\hline $120-130$ & 0 & 2 & 0 & 4 & 0 & 0 & 0 & 0 & 6 \\
\hline $130-140$ & 0 & 2 & 1 & 2 & 0 & 0 & 0 & 0 & 5 \\
\hline $140-150$ & 0 & 4 & 1 & 1 & 0 & 0 & 0 & 0 & 6 \\
\hline $150-160$ & 0 & 9 & 0 & 3 & 0 & 0 & 0 & 0 & 12 \\
\hline TOTAL & 4355 & 120659 & 1126 & 6640 & 736 & 616 & 241 & 318 & 134691 \\
\hline
\end{tabular}

Source: KenHA (2013)

From Table 7, 43\% of vehicles were traveling at an average speed of $55 \mathrm{Km} / \mathrm{hr}$ whilst $23 \%$ of the vehicles were traveling at an average speed of $35 \mathrm{Km} / \mathrm{hr}$. The former speed was mainly achieved during the middle hours of the day and the later during the morning and evening hours when vehicle flow and density were at a maximum. Pedestrians have a $90 \%$ chance of surviving a car crash at $30 \mathrm{~km} / \mathrm{hr}$ or below but less than $50 \%$ chance of surving impacts of $45 \mathrm{~km} / \mathrm{hr}$ or above

Using data in Tables 2 and 7, the current crash rate for Thika Road using was found to be:

$$
\begin{gathered}
c_{r}=\frac{74}{134691 * 365 * 50} * 10^{6}=0.03 \text { Per Million Vehicle } \\
\text { Kilometres Travelled }
\end{gathered}
$$

The crash rate for Thika Road before construction was:

$$
c_{r}=\frac{208}{60000 * 365 * 46} * 10^{6}=0.2 \text { Per Million Vehicle Kilometres }
$$

Accident rates did not necessarily increase with an increase in average speed, but have been found to increase on all classes of roads with an increase in speed variance.

\section{Conclusions}

This study examined the effects of road improvement on safety. Therefore, the analysis compared the trends of road accidents, characteristics of accidents and road features that affect safety before, during and after Thika Road construction. The study established that indeed road rehabilitation, in the case of Thika Road, improved safety by 
minimizing and/or eliminating causes of accidents like: road geometry, lack of pedestrian facilities, bad road surface and inadequate carriageway width and at-grade junctions.Road rehabilitation, however, was found to enhance speed related accidents. This paper has clearly confirmed that safety of road users can be achieved in various ways. Hence with the government's intent to rehabilitate and construct over $10,000 \mathrm{Km}$ of road networks, safety of road users is expected to increase enormously. It was concluded that the driving habits ofmost motorists was not up to standards hence this paper recommends the enhancement of skills drivers and to upgrade the requirements, and competence of PSV drivers on the road.

\section{Recommendations}

The study recommends that the conditions of other roads across Kenya be improved as one way of addressing road safety issues. The traffic department of the National Police Service (MPS) is advised to erect speed guns along the Nairobi-Thika Superhighway and other refurbished roads across the country. This would enable the police to apprehend the motorists who abuse the speed limits, given that this is the major cause of road accidents along improved highways. The study further recommends that all road users particularly motorists should be sensitized on traffic rules. This would hugely reduce traffic road accidents in Kenya.

\section{References}

[1] R. Elvik, and T. Vaa. "TheHandbook ofRoad Safety Measures.” Elsevier, Oxford, UK, 2004.

[2] A.T. de Blaeij, M. Koetse, Y. Tseng, P. Rietveld, and E. Verhoef. "Valuation of safety, time, air pollution, climatechange, and noise; Methods andestimates for variouscountries." Reportfor the EU project ROSEBUD. Vrije Universiteit, Amsterdam, 2004.

[3] Kenya National Bureau of Statistics. "Kenya: 2009 Population and Housing Census Highlights. Nairobi:” Kenya National Bureau of Statistics; 2009.

[4] E.M. Aligula. "A critical Look at management of Transport Sector for efficiency: The challenges and the way forward." $A$ paper presented to the $13^{\text {th }}$ ICPSK Economic Management Symposium, 27 $7^{\text {th }}$ October 2010 at the Sarova Panafric Hotel, Kenya, 2010.

[5] World Health Organization. "Global Burden of Disease: 2004 Update. Geneva, Switzerland:" World Health Organization, 2008.

[6] J.K.Z. Mwatela. "Application of Geographical Information Systems(GIS) To Analyze Causes of Road Traffic Accidents (RTAS)" - "Case Study of Kenya, Presentation in International Conference on Spatial Information for Sustainable Development Nairobi," Kenya $2-5^{\text {th }}$ October 2001.

[7] AASHTO. American Association of State and Highway Transportation Officials. "Highway Safety Manual," Washington, DC, 2010.

[8] G.S. Grant, J.T. Daniel, N.O. Andrewand C.R. Shane. "Transportation Safety Data and Analysis;" Volume1: "Analyzing the Effectiveness of Safety Measures using Bayesian Methods." Report No. UT-10.12a, 2010.

[9] R. P. Roess, E. S. Prassas, and W. W. McShane. "Traffic Engineering," $3^{\text {rd }}$ Ed., Pearson Education, Upper Saddle River, NJ, 2004.

[10] E. Hauer, D. W. Harwood, F.M. Council, and M. S. Griffith. "Estimating safety by the empirical Bayes method: A tutorial." Transportation Research Record. 1784, Transportation Research Board, Washington, DC, 2002, 126-131.

[11] S. Miaou. "The relationship between truck accidents and geometric design of road sections: Poisson versus negative binomial regressions." Accident Analysis \& Prevention, 26(4), 471-82. 1994.

[12] X. Qin, J. N. Ivan, and N. Ravishanker "Selecting exposure measures in crash rate prediction for two-lane highway segments." Accident Analysis and Prevention, 36(2), 183-191, 2004. 